\title{
Self-Referential Thinking, Suicide, and Function of the Cortical Midline Structures and Striatum in Mood Disorders: Possible Implications for Treatment Studies of Mindfulness-Based Interventions for Bipolar Depression
}

\author{
William R. Marchand ${ }^{1,2}$ \\ ${ }^{1}$ Research Service, George E. Wahlen Department of Veterans Affairs Medical Center, Salt Lake City, UT 84148, USA \\ ${ }^{2}$ Department of Psychiatry, The University of Utah, Salt Lake City, UT 84112, USA \\ Correspondence should be addressed to William R. Marchand, wmarchand@me.com
}

Received 2 July 2011; Revised 28 July 2011; Accepted 29 July 2011

Academic Editor: Colombo Cristina

Copyright ( $) 2012$ William R. Marchand. This is an open access article distributed under the Creative Commons Attribution License, which permits unrestricted use, distribution, and reproduction in any medium, provided the original work is properly cited.

\begin{abstract}
Bipolar depression is often refractory to treatment and is frequently associated with anxiety symptoms and elevated suicide risk. There is a great need for adjunctive psychotherapeutic interventions. Treatments with effectiveness for depressive and anxiety symptoms as well as suicide-related thoughts and behaviors would be particularly beneficial. Mindfulness-based interventions hold promise, and studies of these approaches for bipolar disorder are warranted. The aim of this paper is to provide a conceptual background for such studies by reviewing key findings from diverse lines of investigation. Results of that review indicate that cortical midline structures (CMS) appear to link abnormal self-referential thinking to emotional dysregulation in mood disorders. Furthermore, CMS and striatal dysfunction may play a role in the neuropathology underlying suicide-related thoughts and behaviors. Thus, combining studies of mindfulness interventions targeting abnormal self-referential thinking with functional imaging of CMS and striatal function may help delineate the neurobiological mechanisms of action of these treatments.
\end{abstract}

\section{Introduction}

The neurobiology of bipolar spectrum disorders is incompletely characterized [1]. Further, current medication treatments are only partially effective [2], and $73 \%$ of patients receiving pharmacotherapy relapse within 5 years [3]. Thus, there is a compelling need for effective adjunctive psychotherapy interventions $[4,5]$. Cognitive-behavioral therapy is an effective intervention for depression [4, 6-9] but seems to be of less benefit for bipolar spectrum illness [10]. Bipolar disorder is highly comorbid with anxiety [11, 12], and therefore interventions that also target anxiety might be of particular benefit [13]. Mindfulness-based psychotherapies are being increasingly used to target both depressive and anxiety symptoms in a variety of clinical populations [1416]. However, few studies [17-19] have investigated these interventions for bipolar spectrum disorders. Furthermore, an integrated conceptual framework for such studies has not been published.

Mindfulness interventions target aberrant self-referential thinking [20]. Increasing evidence suggests that alterations in self-referential thinking may be associated with a number of mood and anxiety spectrum disorders. For example, investigations indicate an association between aberrant selfconcept and/or self-schemas and unipolar depression [2125], generalized anxiety disorder [26], obsessive-compulsive disorder [27, 28], PTSD [29-31], social phobia [32, 33], and panic disorder [34]. There is evidence that anomalous self-referential thinking is also associated with bipolar spectrum disorders [35-40]. Many studies also indicate that negative self-concept is associated with suicidal behavior [41-51]. One specific brain region, much of the medial 
cortex, is associated with self-referential processing [52, 53]. Some studies have found aberrations in this region to also be associated with suicide [54-57]. Thus, functional abnormalities in medial cortex may be particularly relevant for both self-directed thinking and suicidal behaviors in bipolar spectrum disorders. Studies of this region may be important to completely characterize the neurobiology of these conditions. Furthermore, treatment interventions that target self-referential thinking may have the potential to be efficacious for both decreasing mood symptoms and preventing suicidal behavior. This paper provides an overview of relevant key studies. The goal is to integrate results from diverse lines of investigation and provide a conceptual framework for future studies of self-referential thinking and mindfulness-based in-terventions in bipolar spectrum disorders.

\section{Self-Focused Thinking and Mood Disorders}

There is evidence that the processing of self-referent information is abnormal in both unipolar and bipolar spectrum illness [35, 39, 58, 59]. For example, anomalous self-schemas (beliefs and ideas about self) form the basis for Beck's classic approach to depression [60]. These cognitive theories suggest that psychological symptoms can occur as a result of dysfunctional schemas [61-63]. Schemas are believed to be lasting cognitive structures held in memory that organize thoughts, emotions and behaviors into stable patterns [61]. It has been hypothesized that dysfunctional self-schemas could lead to negative beliefs about self and thus mood symptoms. Multiple studies have focused on the relationship of negative self-esteem and/or schemas to depression [21-25, 58, 64-73], and the effectiveness of interventions targeting negative schemas through cognitive therapy is well established [4, 6-9]. Finally, self-criticism is associated with depression [74-76]. In regard to bipolar spectrum disorders, many [35-38], but not all [77], investigations indicate that aberrant self-concept/schemas are also a characteristic of these conditions. Altered self-esteem persists during remission $[35,39]$ including instability of self-concept [36], which may represent a vulnerability to mood episodes. Finally, a recent study found that higher self-esteem corresponded to better prognosis in refractory bipolar disorder [40].

In addition to abnormalities of self-concept, other facets of self-referential thinking are associated with affective disorders. One of these is the amount of time spent thinking about self. Individuals with unipolar illness have increased self-focused thinking $[78,79]$. The association between the extent of thinking about self and depressive symptoms is undoubtedly complex, and cause and effect relationships may be difficult to determine. However, excessive self-focus in general is associated with negative affect [80], and high levels of self-focus are thought to contribute to depressive pessimism [81]. Finally, cognitive impairment in depression may be associated with increased self-focus [82]. Therefore increased time spent thinking about self might directly contribute to depressive symptoms, at least in unipolar illness.
We are not aware of any studies that have directly addressed this question in bipolar spectrum illness.

In contrast to the extent of self-referential thinking, there is strong evidence that a particular type of thinking about self contributes to dysphoria in general and unipolar depression. Specifically, analytical self-focused rumination (thinking analytically about self and symptoms) is maladaptive [83]. This cognitive style is associated with overgeneral autobiographical memory [84], global negative self-judgments [85], greater negative future thinking [86], and dysphoria [87, 88 ]. Furthermore, there is compelling evidence that ruminative self-focus is associated with both the severity and duration of depressive symptoms [89-95] as well as relapse of ill-ness [96]. There is less research investigating the role of rumina-tion in bipolar spectrum illness, but some evidence suggests that rumination is associated with these conditions as well [97, 98]. Importantly, one study [97] found that rumination predicted the number of depressive episodes, which suggests that treatments targeting rumination might be effective for relapse prevention in bipolar spectrum illness.

In summary, considerable evidence indicates that alterations of self-referential thinking are associated with both unipolar and bipolar spectrum illness. One component is negative self-concept, which is likely associated with depression, regardless of diagnosis. Another facet is rumination about self. In particular, analytic self-focused rumination is maladaptive and may represent a treatment target for bipolar spectrum depression. The implications of this will be discussed in the sections that follow.

\section{Self-Focused Thinking, Rumination, and Suicide-Related Behaviors}

As described above, cognitive theories suggest that suicidal ideation, and other psychological symptoms, can occur as a result of dysfunctional self-schemas and thus negative self-focused thinking [61-63]. As with symptoms of depression, there is considerable evidence of an association between self-referential thinking and suicidal behaviors. Numerous studies have reported an association between self-concept and suicide-related behaviors in a variety of populations [41-51]. Most, but not all [99], suggest that low self-esteem and/or negative beliefs about self are risk factors for suicide or suicidal ideation. In contrast, evidence suggests that posi-tive self-appraisals may confer resilience to suicide [100]. Additionally, individuals who attribute negative life events to external, transient, and specific factors are at decreased risk of suicidal ideation as compared to those who explain undesirable outcomes on internal, stable, and global self-characteristics [101]. However, the relationship is complex because there is evidence that self-esteem is decreased by sui-cide ideation and suicide attempt history [102]. Therefore a dynamic association may exist such that negative self-con-cept and suicidal behaviors are mutually reinforcing over time whereas positive self-referential thinking inhibits suici-dal thinking/behaviors. 
In addition to low self-esteem, other aspects of self-referential thinking patterns have been shown to be associated with suicide. For example, suicide has been posited to serve as an escape from awareness of self [103] and research provides support for this hypothesis [104-106]. According to this model, outcomes that fall short of one's standards and expectations for self are interpreted (self-criticism) as personal inadequacies. This attribution causes self-awareness to become painful and generate negative affect. Suicidal thoughts and behaviors can then occur in response to the individual's desires to escape from both self-awareness and the associated unpleasant affect. Thus, a personality trait of higher levels of self-criticism is likely a risk factor for suiciderelated behaviors $[104,106]$.

Automatic self-associations are another important facet of self-referential thinking. Both automatic associations and explicit beliefs reflect aspects of dysfunctional self-schemas likely related to suicidal thinking. Automatic associations reflect simple associations in memory that activate links between self and specific concepts as opposed to the more complex development of explicit beliefs [107]. It has been shown that automatic self-associations of depression and anxiety are significantly related to both suicidal ideation and past suicide attempts [61].

Automatic self-associations are clinically relevant because they are associated with both symptom expression $[108,109]$ and uncontrolled behaviors [108]. Thus, these associations are thought to drive some spontaneous psychopathological behaviors and contribute to the persistence of psychopathological symptoms $[61,110]$. The association between dysfunctional automatic self-associations and suicidal ideation [61] therefore suggests that these self-associations may contribute to the onset and maintenance of suicidal ideations as well as the difficulty of controlling these thoughts. Automatic associations of self with death are also associated with suicide [111], which suggests another link between this type of memory processing and suicidal thoughts and behaviors.

Finally as is the case for depressive symptoms, there is compelling evidence that rumination is directly associated with suicidal ideation [112-118]. Furthermore, ruminative thinking may partially mediate relationships between both self-criticism [117] and negative life events [118] with suicidality. Rumination leads to greater negative future thinking [86] which might also contribute to suicidal ideation.

The literature reviewed above provides strong evidence that aspects of self-referential thinking are related to suicidal ideations and behaviors in a variety of populations. Few studies have directly addressed this topic among subjects with bipolar spectrum disorders. However, some evidence indicates that facets of self-focused thinking are relevant to suicide in these conditions. For example, low self-esteem lasting into remission seems related to the expression of suicidality during depressive episodes of bipolar patients [119]. Another study suggests that increased ruminations may mediate the association between anxiety and suicidal ideation/behaviors [120]. Future studies are warranted, as it seems likely that self-referential thinking may be related to the expression of depressive symptoms and suicidality irrespective of diagnosis.

\section{The Functional Architecture of Self-Focused Thinking in Mood Disorders}

Most of the anterior and posterior midline cortex has been characterized as an anatomical and functional unit known collectively as the cortical midline structures (CMS) [52]. The CMS are thought to be important in affective disorders because of anatomical connectivity with the amygdala [121125] and striatum [126], both of which are important for emotional processing. Further, the CMS has extensive involvement in both self-referential $[52,53]$ and emotional processing $[127,128]$, and these regions are components of the default mode network $[129,130]$.

Studies using a variety of methodologies suggest that functional alterations exist in the CMS in both unipolar [131-145] and bipolar [146-158] spectrum disorders. More importantly, a growing body of evidence directly links the CMS with both self-referential processing and emotional dysregulation associated with depression. A study of healthy controls demonstrated that self-referential processing activates the CMS and that this neural response is associated with negative affectivity [159]. In unipolar illness, studies indicate that abnormal self-referential processing is mediated by neural response in cortical and subcortical midline structures $[134,160]$. Abnormal CMS neural response during emotional processing has also been demonstrated in unipolar illness $[127,160]$. Furthermore, depressed subjects have increased neural activity during rumination in the CMS, amygdale, and other regions [161]. Finally, depressive symptoms are associated with the degree of CMS activity during a selfnegative judgment task [160]. Thus, a growing body of evidence directly links CMS function to self-referential thinking and rumination in unipolar illness, and it appears likely that CMS structures play a key role in mediating the relationship between excessive self-referential thinking and negative affect.

The potential role of the CMS in emotional dysregulation and self-referential thinking is not as well characterized in bipolar spectrum disorders. However, a number of function imaging studies using emotional activation paradigms suggest a relationship between CMS function and emotional dysregulation in depression [147, 148, 155], mania [156158], as well as euthymia [162]. Most investigations have studied bipolar I disorder; however, our group recently reported evidence of CMS-mediated emotional dysregulation in bipolar II disorder [153]. Finally, there is also some evidence of changes in CMS activation associated with treatment response [152, 163-165]. To our knowledge, aberrant selfreferential processing in bipolar disorder has not yet been investigated using functional neuroimaging methods.

In summary, compelling functional imaging evidence indicates that CMS dysfunction in unipolar illness is associated with self-referential thinking and emotional regulation in unipolar illness. Further, the CMS likely mediates interactions between self-focused cognitions and emotional symptom expression. In bipolar disorders, considerable evidence indicates that CMS function is related to emotional dysregulation. Neuroimaging studies of self-referential processing in bipolar spectrum conditions are warranted. 


\section{The Role of the Striatum and CMS in Suicide-Related Thoughts and Behaviors}

A large literature documents the role of striatal and associated corticobasal ganglia circuitry dysfunction in affective disorders, see [166, 167] for recent reviews. Recent studies also implicate striatal dysfunction in the neurobiology of suicide-related thoughts and behaviors in both bipolar [168] and unipolar spectrum disorders [169-171] as well as among those with alcohol dependence [172]. In regard to the CMS, there is structural, functional imaging [54] and molecular [55-57] evidence that dysfunction in this region may also be related to suicide.

The striatum and CMS have extensive anatomical [126, 173] and functional [174] connectivity. Importantly, striatalCMS connectivity has been shown to be disrupted in bipolar II depression [168]. Finally, aberrant functional connectivity of the striatum with the posterior medial cortex has been shown to correlate with depression severity [168].

Taken together, these studies suggest that both CMS and striatal dysfunction may be relevant for suicide. Future investigations of the potential role of these regions in suiciderelated behaviors are warranted. In particular, additional investigations of functional connectivity between the two regions may provide important insights.

\section{Implications for Studies of Self-Referential Processing and Suicide in Bipolar Spectrum Depression}

A primary aim of this manuscript is to integrate results of diverse key studies in order to provide a conceptual framework for future investigations of bipolar depression. Conclusions from the investigations reviewed herein are summarized in Table 1.

It is now well established that aspects of aberrant selfreferential thinking contribute to the symptoms of unipolar depression. The strongest evidence is for analytical selffocused rumination. However, the amount of time spent thinking about the self may also be relevant. Studies clearly demonstrate that CMS play primary role in self-referential thinking. Additionally, there is strong evidence the CMS dysfunction plays a direct role in emotional dysregulation in unipolar depression and likely mediates the relationship between self-focused thinking and emotional dysregulation in this disorder. Finally, abnormalities of both the striatum and CMS may contribute to suicide risk in affective illness and the functional connectivity between the new regions may be of particular relevance.

In regard to bipolar disorder, there is relatively strong evidence of aberrations of both self-referential thinking and CMS function. Further, CMS dysfunction appears to be associated with deficits of emotional regulation. It is unclear if self-focused thinking and emotion dysregulation are linked by the CMS, as is the case for unipolar depression. However, this possibility clearly warrants investigation. Studies of the potential roles of both the striatum and CMS in suicide are indicated as well.
Future studies, as suggested above, may enhance our understanding of the neurobiology of bipolar depression. More importantly, it is possible that a subregion of the CMS might mediate relationships between self-referential thinking, emotional dysregulation, and suicidality. Such a finding would likely be very relevant for the development of bio markers as well as treatment interventions.

\section{Implications for Bipolar Depression Treatment Studies Using Mindfulness Interventions}

The studies reviewed herein have implications for studying neurobiological mechanisms in bipolar depression as described above. More importantly, these investigations support studies of mindfulness-based treatment interventions that specifically focus on altered self-referential processing.

There is not yet complete consensus as to how the concept of mindfulness should be properly operationalized in Western psychology, and such lack of consensus is reflected into the multiplicity of definitions of mindfulness employed by different authors concerned with mindfulness-based interventions, for example [175]. However, mindfulness is usually described as a practice through which one learns to focus attention on moment-by-moment experience with an attitude of curiosity, openness, and acceptance. Practicing mindfulness is simply experiencing the present moment, without trying to change anything $[20,176]$. During mindfulness, awareness is focused on external sensory inputs, such as auditory, olfactory, and visual stimuli, as well as internal sensations, such as proprioception and pain. Furthermore, attention is specifically focused on awareness of the internal workings of the mind [20].

Although an increasing number of mindfulness-based interventions are currently employed for a large variety of psychiatric disorders, two such interventions, mindfulnessbased stress reduction (MBSR) and mindfulness-based cognitive therapy (MBCT), have proven to be particularly fruitful approaches for many of these conditions. The concept of mindfulness originated in Buddhist spiritual practices [177]; however, both MBSR and MBCT are secular, clinically based methods utilizing manuals and standardized techniques. MBSR was developed by Dr. Kabat-Zinn at the University of Massachusetts Medical Center [20]. MBSR includes education about stress as well as training on coping strategies and assertiveness in addition to mindfulness. The mindfulness component includes sitting meditation, a body scan (focusing on bodily sensations), and Hatha Yoga. MBSR involves the cultivation of a number of attitudes, including becoming an impartial witness to one's own experience and acceptance of things as they actually are in the present moment [20]. MBCT was developed by Segal et al. [178]. MBCT is based upon MBSR and combines the principles of cognitive therapy with those of mindfulness to prevent relapse of depression. MBCT, like MBSR, utilizes secular mindfulness techniques including seated meditation. The program specifically teaches recognition of deteriorating mood with the aim of disengaging from self-perpetuating 
TABLE 1: Conclusions from studies reviewed.

(i) Abnormalities of self-referential processing are likely a general characteristic of mood disorders

(ii) Increased self-focused thinking may contribute to depressive symptoms

(iii) Analytical self-focused rumination clearly contributes to the manifestation of depression in unipolar illness and possibly in bipolar spectrum depression

(iv) Aspects of aberrant self-focused thinking (particularly rumination) likely contribute to suicide-related behaviors and thoughts in unipolar depression

(v) The cortical midline structures (CMS) play a key role in both self-referential thinking and emotional regulation

(vi) Functional abnormalities of the CMS are likely a characteristic of mood disorders in general

(vii) In unipolar illness, CMS function plays a role in dysregulation of both self-referential thinking and emotion and likely mediates the relationship between the two

(viii) Dysfunction of both the striatum and CMS are likely involved in the neurobiology of suicide-related thoughts and behaviors

(ix) Abnormal functional connectivity between the striatum and CMS may be relevant for both the expression of both depressive symptoms and suicide

patterns of ruminative, negative thought that contribute to relapse [178].

A very large literature supports the effectiveness of MBSR on several psychological outcomes. Examples include studies of social anxiety disorder [179], generalized anxiety disorder [180], insomnia [181], psychological functioning among individuals with a large variety of medical disorders [182$186]$ including fibromyalgia $[187,188]$, cancer $[182,186$, 189-192], gay men living with HIV [193], and pain [183, 187, 194-197] as well as healthy individuals [198]. Evidence indicates that MBCT is beneficial for unipolar depression relapse prevention [199-204], generalized anxiety disorder [180], panic disorder [205], hypochondriasis [206], and social phobia [207]. The strongest evidence is for relapse prevention in unipolar illness. A recent meta-analysis [208] concluded that MBCT was significantly better than usual care for reducing relapses in those with three or more prior episodes. Additional conclusions were that effectiveness for relapse prevention was similar to antidepressants at one year and that augmentation with MBCT could be useful for reducing residual depressive symptoms. A subsequent study [204] provided compelling evidence confirming that for depressed patients, MBCT offers protection against relapse equal to that of maintenance antidepressant pharmacotherapy. Further, a recent review and meta-analysis [15] specifically addressed the effectiveness of MBSR and MBCT (and similar interventions) for reducing symptoms of anxiety and depression. The authors concluded that mindfulness-based therapy improves symptoms of anxiety and depression across a wide range of severity and even when these symptoms are associated with other disorders [15]. This study supports the use of these interventions for acute treatment as well as relapse prevention. Finally, there is evidence of effectiveness of MBCT for depression among both symptomatic and partially symptomatic patients [209].

These studies suggest that both MBSR and MBCT have broad-spectrum antidepressant and antianxiety effectiveness. Furthermore, preliminary evidence suggests that MBCT is feasible for use in bipolar disorder and may decrease symptoms of anxiety and depression [17-19]. Of note, one of these investigations [17] specifically studied individuals who had previously experienced serious suicidal ideation. Finally, evidence is accumulating in support of the use of mindfulness interventions for suicide prevention [210-213], and additional research is ongoing [214].

The studies citied above indicate that additional trials of mindfulness interventions for bipolar spectrum disorders are warranted. In particular, studies of acute and maintenance treatment of depressive and anxiety symptoms as well as suicide prevention are warranted.

The possibility that mindfulness interventions may help prevent suicide is particularly intriguing. In bipolar spectrum disorders, severity of affective episodes [215] comorbid panic [216], and psychosocial stress [217] are suicide risk factors. Thus, mindfulness interventions might decrease suicide risk through more than one mechanism.

\section{Neuroimaging of Mindfulness: Implications for Studies of Bipolar Depression}

Neuroimaging studies of mindfulness add to the evidence supporting trials of mindfulness interventions for bipolar depression. Furthermore, these studies suggest specific investigations that could be aimed at exploring the neural mechanisms underlying any observed benefits.

As described above, the CMS play a key role in both selfreferential and emotional processing [52, 53, 127, 128]. Further, evidence indicates that CMS structures play a direct role in mediating the relationship between self-referential thinking and negative affect in mood disorders [127, 134, 147, 148, 153, 155-162]. A number of structural and functional neuroimaging as well as electroencephalogram (EEG) studies have provided information about the neural processes underlying mindfulness practices. Some key findings are reviewed herein, for a more detailed recent review, see [218].

Zen meditation is a mindfulness practice that has been studied using neuroimaging methods. Zen is a traditional Buddhist approach to mindfulness [219, 220]. Zen primarily involves the practice of developing mindfulness by way of seated meditation $[219,220]$. During meditation periods, 
known as Zazen, practitioners sit silently without moving on either a cushion or in a chair [220]. It is important to note that while Zen meditation is a Buddhist practice, it is frequently practiced as a secular means to achieve mindfulness [221].

A number of investigations indicate that Zen meditation induces changes in brain function measurable by both functional MRI (fMRI) and EEG [222-228]. One fMRI study [228] of regular Zen practitioners and matched control subjects found that Zen practitioners displayed a reduced duration of the neural response linked to conceptual processing in regions of the default network, including a portion of the CMS. The authors concluded that that meditative training fosters the ability to control the automatic cascade of semantic associations triggered by a stimulus or, in other words, voluntarily regulate the flow of spontaneous mentation. This study suggests that the practice of Zen meditation may facilitate the ability to regulate self-referential thinking by consciously modulating the function of the CMS and other brain regions.

In addition to functional changes, evidence also indicates that extended Zen practice is associated with changes in brain morphology. In one study [229], structural MRI scans were performed and pain tolerance was assessed in meditators and controls. Meditators had significantly lower pain sensitivity than controls. Furthermore, meditators were found to have thicker cortex in a CMS region (dorsal anterior cingulate) and other areas and more years of meditation experience was associated with thicker gray matter in the anterior cingulate. This study provides compelling evidence that a mindfulness practice can impact CMS structure in addition to effects on function as demonstrated by other studies [222-228]. Another study [230] examined how the regular practice of Zen meditation might affect the normal age-related decline of cerebral gray matter volume and attentional per-formance observed in healthy individuals. Structural MRI and a computerized sustained attention task were used to study regular practitioners of Zen meditation and controls. Control subjects displayed the expected negative correlation of both gray matter volume and attentional performance with age. However, in contrast, meditators did not show a significant correlation of either measure with age. The effect of meditation on gray matter volume was most prominent in the putamen. The authors conclude that these findings suggest that the regular practice of meditation may have neuroprotective effects and reduce the cognitive decline associated with normal aging.

Several studies of mindfulness and other meditation practices also indicate these methods impact CMS function [231-235]. For example, Vipassana is a mindfulness technique that has similarities to Zen meditation, but has a particular focus on introspection, contemplation, and the development of insight [236]. An fMRI study [235] of this practice also revealed differences in CMS activation among meditators as compared to controls.

In addition to the investigations described above, MBSR has also been studied using functional and structural neuro imaging. One study [237] found that prior to MBSR training, experiential focus (mindfulness) was associated with decreased CMS activation as compared to narrative focus. After MBSR training, experiential focus resulted in marked and pervasive reductions of CMS activation along with increased engagement of other regions. Further analyses demonstrated uncoupling of right insula and CMS connectivity in response to MBSR. This study provides compelling direct evidence that neural process underlying mindfulness involves both CMS activation and connectivity with other regions. Another study [238] recently demonstrated that this practice resulted in altered connectivity between anterior CMS regions and sensory cortex, which may indicate greater reflective awareness for sensory experience as a result of MBSR. In regard to structural imaging, recent studies [239, 240] indicate that MBSR, like Zen, also alters brain morphology. One study [239] found changes in gray matter concentration in the CMS as well as left hippocampus, the temporoparietal junction and the cerebellum. Thus in addition to impacting the CMS, mindfulness practices may decrease emotional reactivity by modulating other mechanisms as well. At least two other studies also support this conclusion. A recent study [179] reported decreased amygdala activation as a result of patients receiving MBSR for social anxiety disorder. Another study indicated that reductions in perceived stress correlated positively with decreases in right basolateral amygdala gray matter density in response to MBSR [240].

As described above, compelling evidence now exists demonstrating that mindfulness practices impact both the structure and function of the CMS as well as other regions. Furthermore, sadness is associated with CMS activation and mindfulness training changes the neural response associated with this emotion [241]. Taken together, the studies reviewed herein suggest a hypothesis of the neural mechanisms underlying any beneficial effects mindfulness practices may provide for bipolar depression. Specifically, these interventions likely exert benefit, at least in part, by modulating CMS functions associated with both self-referential thinking and emotional regulation. Thus, studies of mindfulness practices for bipolar disorder may benefit from a functional imaging component aimed at exploring CMS activation and connectivity. Such studies should also evaluate striatal function because meditation impacts this region $[230,232]$ as well as the fact that dysfunction of this area is associated with both affective illness $[166,167]$ and suicide [54-57, 168-172].

\section{Conclusions}

Bipolar disorder is a disabling [242-244] and difficult to treat [245-248] condition. In particular, bipolar depression is a source of considerable suffering [249, 250] and is often associated with anxiety [251, 252] and increased suicidal risk $[249,250,253,254]$. Current treatments are often only partially effective [2], and relapse is a common occurrence $[2,3]$. Adjunctive psychotherapy approaches are needed that are effective for 
depressive and anxiety symptoms as well as suicide prevention.

Converging lines of clinical evidence reviewed herein indicate that mindfulness-based interventions, such as MBSR and MBCT, hold great promise as psychotherapeutic interventions for bipolar depression. From the clinical perspective, there is compelling evidence that MBSR and MBCT have broad-spectrum effectiveness for anxiety and depressive symptoms [15, 179-209]. Additionally, evidence now specifically indicates that MBCT is feasible for use in bipolar disorder and decreases symptoms of both anxiety and depression [17-19]. Finally, evidence is accumulating in support of the use of mindfulness interventions for suicide prevention [210-213]. Thus, investigations of mindfulness-based interventions for bipolar spectrum disorders are clearly warranted as these approaches have the potential to decrease symptoms of depression and anxiety as well as suicide risk.

In addition to the clinical evidence, psychological and neurobiological studies come together suggesting a hypothetical mechanism of action for mindfulness practices in the treatment of bipolar disorders. Specifically, the processing of self-referent information is abnormal in affective disorders $[35,39,58,59]$. The CMS play a key role in both self-referential [52, 53] and emotional processing [127, 128], and a growing body of evidence indicates that CMS structures play a direct role in mediating the relationship between selfreferential thinking and negative affect in mood disorders [127, 134, 147, 148, 153, 155-162]. Mindfulness interventions target aberrant self-referential thinking [20], and neuroimaging studies indicate that mindfulness practices impact both structure and function of CMS [228, 229, 231235, 237-239]. Thus, these interventions likely exert benefit, at least in part, by modulating CMS functions associated with both self-referential thinking and emotional regulation. Studies of mindfulness practices for bipolar disorder should include a functional imaging component aimed at exploring CMS activation and connectivity. These studies should also evaluate striatal function because meditation impacts this region $[230,232]$ as well as the fact that dysfunction of this area is associated with both affective illness $[166,167]$ and suicide [54-57, 168-172]. Such investigation could provide important insights into how mental training can affect the cognitive and emotional dysfunctions typically observed in patients with affective disorders.

\section{Acknowledgments}

This paper was supported by a Department of Veterans Affairs Career Development Award. Additional support was provided by the resources and the use of facilities at the VA Salt Lake City Health Care System.

\section{References}

[1] M. A. Cerullo, C. M. Adler, M. P. Delbello, and S. M. Strakowski, "The functional neuroanatomy of bipolar disorder," International Review of Psychiatry, vol. 21, no. 4, pp. 314-322, 2009.
[2] R. M. Post, L. L. Altshuler, M. A. Frye et al., "Complexity of pharmacologic treatment required for sustained improvement in outpatients with bipolar disorder," Journal of Clinical Psychiatry, vol. 71, no. 9, pp. 1176-1186, 2010.

[3] M. J. Gitlin, J. Swendsen, T. L. Heller, and C. Hammen, "Relapse and impairment in bipolar disorder," American Journal of Psychiatry, vol. 152, no. 11, pp. 1635-1640, 1995.

[4] S. D. Lauder, M. Berk, D. J. Castle, S. Dodd, and L. Berk, "The role of psychotherapy in bipolar disorder," Medical Journal of Australia, vol. 193, no. 4, pp. S31-S35, 2010.

[5] D. J. Miklowitz, "Adjunctive psychotherapy for bipolar disorder: state of the evidence," American Journal of Psychiatry, vol. 165, no. 11, pp. 1408-1419, 2008.

[6] C. J. Gibbons, J. C. Fournier, S. W. Stirman, R. J. Derubeis, P. Crits-Christoph, and A. T. Beck, "The clinical effectiveness of cognitive therapy for depression in an outpatient clinic," Journal of Affective Disorders, vol. 125, no. 1-3, pp. 169-176, 2010.

[7] Work Group On Major Depressive Disorder, American Psychiatric Association Practice Guideline For The Treatment of Patients With Major Depressive Disorder, American Psychiatric Publishing, Arlington, Va, USA, 2010.

[8] J. H. Wright, A. T. Beck, and M. E. Thase, "Cognitive therapy," in Textbook of Clinical Psychiatry, R. E. Hales and S. C. Yudofsky, Eds., pp. 1245-1284, American Psychiatric Publishing, Washington, DC, USA, 2003.

[9] S. Jones, "Psychotherapy of bipolar disorder: a review," Journal of Affective Disorders, vol. 80, no. 2-3, pp. 101-114, 2004.

[10] J. Scott, E. Paykel, R. Morriss et al., "Cognitive-behavioural therapy for severe and recurrent bipolar disorders: randomised controlled trial," British Journal of Psychiatry, vol. 188, pp. 313-320, 2006.

[11] N. M. Simon, M. W. Otto, S. R. Wisniewski et al., "Anxiety disorder comorbidity in bipolar disorder patients: data from the first 500 participants in the systematic treatment enhancement program for bipolar disorder (STEP-BD)," American Journal of Psychiatry, vol. 161, no. 12, pp. 2222-2229, 2004.

[12] A. Zutshi, Y. C. J. Reddy, K. Thennarasu, and C. R. Chandrashekhar, "Comorbidity of anxiety disorders in patients with remitted bipolar disorder," European Archives of Psychiatry and Clinical Neuroscience, vol. 256, no. 7, pp. 428-436, 2006.

[13] M. D. Provencher, L. D. Hawke, and E. Thienot, "Psychotherapies for comorbid anxiety in bipolar spectrum disorders," Journal of Affective Disorders, vol. 133, no. 3, pp. 371-380, 2011.

[14] A. Chiesa and A. Serretti, "A systematic review of neurobiological and clinical features of mindfulness meditations," Psychological Medicine, vol. 40, no. 8, pp. 1239-1252, 2010.

[15] S. G. Hofmann, A. T. Sawyer, A. A. Witt, and D. Oh, "The effect of mindfulness-based therapy on anxiety and depression: a meta-analytic review," Journal of Consulting and Clinical Psychology, vol. 78, no. 2, pp. 169-183, 2010.

[16] B. Ivanovski and G. S. Malhi, "The psychological and neurophysiological concomitants of mindfulness forms of meditation," Acta Neuropsychiatrica, vol. 19, no. 2, pp. 76-91, 2007.

[17] J. M. G. Williams, Y. Alatiq, C. Crane et al., "Mindfulnessbased cognitive therapy (MBCT) in bipolar disorder: preliminary evaluation of immediate effects on between-episode functioning," Journal of Affective Disorders, vol. 107, no. 1-3, pp. 275-279, 2008. 
[18] B. Weber, F. Jermann, M. Gex-Fabry, A. Nallet, G. Bondolfi, and J. M. Aubry, "Mindfulness-based cognitive therapy for bipolar disorder: a feasibility trial," European Psychiatry, vol. 25, no. 6, pp. 334-337, 2010.

[19] P. Chadwick, H. Kaur, M. Swelam, S. Ross, and L. Ellett, "Experience of mindfulness in people with bipolar disorder: a qualitative study," Psychotherapy Research, vol. 21, no. 3, pp. 277-285, 2011.

[20] J. Kabat-Zinn, Full Catastrophe Living: Using the Wisdom of Your Body and Mind to Face Stress, Pain, and Illness, Bantam Dell, New York, NY, USA, 2005.

[21] J. Evans, J. Heron, G. Lewis, R. Araya, and D. Wolke, "Nega tive self-schemas and the onset of depression in women: longitudinal study," British Journal of Psychiatry, vol. 186, pp. 302-307, 2005.

[22] L. Miller, V. Warner, P. Wickramaratne, and M. Weissman, "Self-esteem and depression: ten year follow-up of mothers and offspring," Journal of Affective Disorders, vol. 52, no. 1-3, pp. 41-49, 1999.

[23] C. A. King, M. W. Naylor, H. G. Segal, T. Evans, and B. N. Shain, "Global self-worth, specific self-perceptions of competence, and depression in adolescents," Journal of the American Academy of Child and Adolescent Psychiatry, vol. 32, no. 4, pp. 745-752, 1993.

[24] R. B. Schafer and P. M. Keith, "Self-esteem discrepancies and depression," The Journal of Psychology, vol. 109, no. 1, pp. 4349, 1981.

[25] G. W. Brown, B. Andrews, and T. Harris, "Social support, self-esteem and depression," Psychological Medicine, vol. 16, no. 4, pp. 813-831, 1986.

[26] E. R. Henning, C. L. Turk, D. S. Mennin, D. M. Fresco, and R. G. Heimberg, "Impairment and quality of life in individuals with generalized anxiety disorder," Depression and Anxiety, vol. 24, no. 5, pp. 342-349, 2007.

[27] K. A. Ehntholt, P. M. Salkovskis, and K. A. Rimes, "Obsessivecompulsive disorder, anxiety disorders, and self-esteem: an exploratory study," Behaviour Research and Therapy, vol. 37, no. 8, pp. 771-781, 1999.

[28] K. D. Wu, L. A. Clark, and D. Watson, "Relations between obsessive-compulsive disorder and personality: beyond Axis I-Axis II comorbidity," Journal of Anxiety Disorders, vol. 20, no. 6, pp. 695-717, 2006.

[29] T. B. Kashdan, W. E. Breen, and T. Julian, "Everyday strivings in war veterans with posttraumatic stress disorder: suffering from a hyper-focus on avoidance and emotion regulation," Behavior Therapy, vol. 41, no. 3, pp. 350-363, 2010.

[30] J. A. Boscarino and R. E. Adams, "PTSD onset and course following the World Trade Center disaster: findings and implications for future research," Social Psychiatry and Psychiatric Epidemiology, vol. 44, no. 10, pp. 887-898, 2009.

[31] T. B. Kashdan, G. Uswatte, M. F. Steger, and T. Julian, "Fragile self-esteem and affective instability in posttraumatic stress disorder," Behaviour Research and Therapy, vol. 44, no. 11, pp. 1609-1619, 2006.

[32] C. Acarturk, F. Smit, R. De Graaf, A. Van Straten, M. Ten Have, and P. Cuijpers, "Incidence of social phobia and identification of its risk indicators: a model for prevention," Acta Psychiatrica Scandinavica, vol. 119, no. 1, pp. 62-70, 2009.

[33] F. Izgiç, G. Akyüz, O. Doğan, and N. Kuğu, "Social phobia among university students and its relation to self-esteem and body image," Canadian Journal of Psychiatry, vol. 49, no. 9, pp. 630-634, 2004.

[34] N. M. Batelaan, R. de Graaf, J. Spijker et al., "The course of panic attacks in individuals with panic disorder and subthreshold panic disorder: a population-based study," Journal of Affective Disorders, vol. 121, no. 1-2, pp. 30-38, 2010.
[35] K. K. Nilsson, C. R. Jørgensen, T. K. J. Craig, K. N. Straarup, and R. W. Licht, "Self-esteem in remitted bipolar disorder patients: a meta-analysis," Bipolar Disorders, vol. 12, no. 6, pp. 585-592, 2010.

[36] R. Knowles, S. Tai, S. H. Jones, J. Highfield, R. Morriss, and R. P. Bentall, "Stability of self-esteem in bipolar disorder: comparisons among remitted bipolar patients, remitted unipolar patients and healthy controls," Bipolar Disorders, vol. 9, no. 5, pp. 490-495, 2007.

[37] B. Pavlova, R. Uher, L. Dennington, K. Wright, and C. Donaldson, "Reactivity of affect and self-esteem duringremission in bipolar affective disorder: an experimentalinvestigation," Journal of Affective Disorders, vol. 134, no. 1-3, pp. 102-111, 2011.

[38] S. L. Johnson, B. Meyer, C. Winett, and J. Small, "Social support and self-esteem predict changes in bipolar depression but not mania," Journal of Affective Disorders, vol. 58, no. 1, pp. 79-86, 2000.

[39] S. Blairy, S. Linotte, D. Souery et al., "Social adjustment and self-esteem of bipolar patients: a multicentric study," Journal of Affective Disorders, vol. 79, no. 1-3, pp. 97-103, 2004.

[40] A. Gonzalez-Isasi, E. Echeburua, J. M. Liminana, and A. Gonzalez-Pinto, "Predictors of good outcome in patients with refractory bipolar disorder after a drug or a drug and cognitive-behavioral treatment," Comprehensive Psychiatry. In press.

[41] A. C. Au, S. Lau, and M. T. Lee, "Suicide ideation and depression: the moderation effects of family cohesion and social self-concept," Adolescence, vol. 44, no. 176, pp. 851868, 2009.

[42] S. Bar, M. Ghahramanlou-Holloway, G. Brown, and A. T. Beck, "Self-esteem and suicide ideation in psychiatric outpatients," Suicide and Life-Threatening Behavior, vol. 38, no. 5, pp. 511-516, 2008.

[43] D. F. Becker and C. M. Grilo, "Prediction of suicidality and violence in hospitalized adolescents: comparisons by sex," Canadian Journal of Psychiatry, vol. 52, no. 9, pp. 572-580, 2007.

[44] B. J. Cox, M. W. Enns, and I. P. Clara, "Psychological dimensions associated with suicidal ideation and attempts in the national comorbidity survey," Suicide and Life-Threatening Behavior, vol. 34, no. 3, pp. 209-219, 2004.

[45] C. W. M. Kienhorst, E. J. De Wilde, J. Van den Bout, R. F. W. Diekstra, and W. H. G. Wolters, "Characteristics of suicide attempters in a population-based sample of Dutch adolescents," British Journal of Psychiatry, vol. 156, pp. 243248, 1990.

[46] E. Evans, K. Hawton, and K. Rodham, "Factors associated with suicidal phenomena in adolescents: a systematic review of population-based studies," Clinical Psychology Review, vol. 24, no. 8, pp. 957-979, 2004.

[47] J. A. Kuhlberg, J. B. Peña, and L. H. Zayas, "Familism, parentadolescent conflict, self-esteem, internalizing behaviors and suicide attempts among adolescent Latinas," Child Psychiatry and Human Development, vol. 41, no. 4, pp. 425-440, 2010.

[48] J. C. Overholser, D. M. Adams, K. L. Lehnert, and D. C. Brinkman, "Self-esteem deficits and suicidal tendencies among adolescents," Journal of the American Academy of Child and Adolescent Psychiatry, vol. 34, no. 7, pp. 919-928, 1995.

[49] J. C. Santos, C. B. Saraiva, and L. de Sousa, "The role of expressed emotion, self-concept, coping, and depression in 
parasuicidal behavior: a follow-up study," Archives of Suicide Research, vol. 13, no. 4, pp. 358-367, 2009.

[50] A. H. Thompson, "The suicidal process and self-esteem," Crisis, vol. 31, no. 6, pp. 311-316, 2010.

[51] L. G. Wild, A. J. Flisher, and C. Lombard, "Suicidal ideation and attempts in adolescents: associations with depression and six domains of self-esteem," Journal of Adolescence, vol. 27, no. 6, pp. 611-624, 2004.

[52] G. Northoff and F. Bermpohl, "Cortical midline structures and the self," Trends in Cognitive Sciences, vol. 8, no. 3, pp. 102-107, 2004.

[53] G. Northoff, A. Heinzel, M. de Greck, F. Bermpohl, H. Dobrowolny, and J. Panksepp, "Self-referential processing in our brain-A meta-analysis of imaging studies on the self," NeuroImage, vol. 31, no. 1, pp. 440-457, 2006.

[54] T. Reisch, E. Seifritz, F. Esposito, R. Wiest, L. Valach, and K. Michel, "An fMRI study on mental pain and suicidal behavior," Journal of Affective Disorders, vol. 126, no. 1-2, pp. 321-325, 2010.

[55] M. Leyton, V. Paquette, P. Gravel et al., “ $\alpha$-[11C]methyl-Ltryptophan trapping in the orbital and ventral medial prefrontal cortex of suicide attempters," European Neuropsychopharmacology, vol. 16, no. 3, pp. 220-223, 2006.

[56] D. M. Cannon, M. Ichise, S. J. Fromm et al., "Serotonin transporter binding in bipolar disorder assessed using [11C]DASB and positron emission tomography," Biological Psychiatry, vol. 60, no. 3, pp. 207-217, 2006.

[57] M. A. Oquendo, G. P. A. Placidi, K. M. Malone et al., "Positron emission tomography of regional brain metabolic responses to a serotonergic challenge and lethality of suicide attempts in major depression," Archives of General Psychiatry, vol. 60, no. 1, pp. 14-22, 2003.

[58] M. A. Gara, R. L. Woolfolk, B. D. Cohen, R. B. Goldston, L. A. Allen, and J. Novalany, "Perception of self and other in major depression," Journal of Abnormal Psychology, vol. 102, no. 1, pp. 93-100, 1993.

[59] A. Y. Shestyuk and P. J. Deldin, "Automatic and strategic representation of the self in major depression: trait and state abnormalities," American Journal of Psychiatry, vol. 167, no. 5, pp. 536-544, 2010.

[60] A. T. Beck, Depression: Clinical, Experimental, and Theoretical Aspects, Harper \& Row, New York, NY, USA, 1967.

[61] K. A. Glashouwer, P. J. De Jong, B. W. J. H. Penninx, A. J. F. M. Kerkhof, R. Van Dyck, and J. Ormel, "Do automatic self-associations relate to suicidal ideation?" Journal of Psychopathology and Behavioral Assessment, vol. 32, no. 3, pp. 428-437, 2010.

[62] T. E. Ellis, Cognition and Suicide: Theory, Research, and Therapy, American Psychological Association, Washington, DC, USA, 2006.

[63] M. A. Weishaar and A. T. Beck, "Clinical and cognitive predictors of suicide," in Assessment and Prediction of Suicide, R. W. Maris, A. L. Berman, J. T. Maltsberger, and R. I. Yufit, Eds., pp. 467-438, Guilford, New York, NY, USA, 1992.

[64] D. W. Kreger, "Self-esteem, stress, and depression among graduate students," Psychological Reports, vol. 76, no. 1, pp. 345-346, 1995.

[65] D. Sheslow, S. Hassink, W. Wallace, and E. DeLancey, "The relationship between self-esteem and depression in obese children," Annals of the New York Academy of Sciences, vol. 699, pp. 289-291, 1993.

[66] W. Patton, "Relationship between self-image and depression in adolescents," Psychological Reports, vol. 68, no. 3, pp. 867870, 1991.
[67] M. Workman and J. Beer, "Self-esteem, depression, and alcohol dependency among high school students," Psychological Reports, vol. 65, no. 2, pp. 451-455, 1989.

[68] G. W. Brown, A. Bifulco, H. O. F. Veiel, and B. Andrews, "Selfesteem and depression. II. Social correlates of self-esteem," Social Psychiatry and Psychiatric Epidemiology, vol. 25, no. 5, pp. 225-234, 1990.

[69] G. W. Brown, A. Bifulco, and B. Andrews, "Self-esteem and depression. III. Aetiological issues," Social Psychiatry and Psychiatric Epidemiology, vol. 25, no. 5, pp. 235-243, 1990.

[70] G. W. Brown, A. Bifulco, and B. Andrews, "Self-esteem and depression. IV. Effect on course and recovery," Social Psychiatry and Psychiatric Epidemiology, vol. 25, no. 5, pp. 244249, 1990.

[71] G. W. Brown, B. Andrews, A. Bifulco, and H. Veiel, "Selfesteem and depression. 1. Measurement issues and prediction of onset," Social Psychiatry and Psychiatric Epidemiology, vol. 25, no. 4, pp. 200-209, 1990.

[72] C. Hammen, "Self-cognitions, stressful events, and the prediction of depression in children of depressed mothers," Journal of Abnormal Child Psychology, vol. 16, no. 3, pp. 347-360, 1988.

[73] J. Battle, "Relationship between self-esteem and depression among high school students," Perceptual and Motor Skills, vol. 51, no. 1, pp. 157-158, 1980.

[74] P. Luyten, B. Sabbe, S. J. Blatt et al., "Dependency and selfcriticism: relationship with major depressive disorder, severity of depression, and clinical presentation," Depression and Anxiety, vol. 24, no. 8, pp. 586-596, 2007.

[75] R. M. Bagby, B. J. Cox, D. R. Schuller, A. J. Levitt, R. P. Swinson, and R. T. Joffe, "Diagnostic specificity of the dependent and self-critical personality dimensions in major depression," Journal of Affective Disorders, vol. 26, no. 1, pp. 59-63, 1992.

[76] M. Mongrain and F. Leather, "Immature dependence and self-criticism predict the recurrence of major depression," Journal of Clinical Psychology, vol. 62, no. 6, pp. 705-713, 2006.

[77] D. Pardoen, F. Bauwens, A. Tracy, F. Martin, and J. Mendlewicz, "Self-esteem in recovered bipolar and unipolar outpatients," British Journal of Psychiatry, vol. 163, pp. 755-762, 1993.

[78] R. E. Ingram, "Self-focused attention in clinical disorders: review and a conceptual model," Psychological Bulletin, vol. 107, no. 2, pp. 156-176, 1990.

[79] G. Northoff, "Psychopathology and pathophysiology of the self in depression-neuropsychiatric hypothesis," Journal of Affective Disorders, vol. 104, no. 1-3, pp. 1-14, 2007.

[80] M. Nilly and J. Winquist, "Self-focused attention and negative affect: a meta-analysis," Psychological Bulletin, vol. 128, no. 4, pp. 638-662, 2002.

[81] T. Pyszczynski, K. Holt, and J. Greenberg, "Depression, selffocused attention, and expectancies for positive and negative future life events for self and others," Journal of Personality and Social Psychology, vol. 52, no. 5, pp. 994-1001, 1987.

[82] S. Strack, P. H. Blaney, R. J. Ganellen, and J. C. Coyne, "Pessimistic self-preoccupation, performance deficits, and depression," Journal of Personality and Social Psychology, vol. 49, no. 4, pp. 1076-1085, 1985.

[83] J. D. Teasdale, "Emotional processing, three modes of mind and the prevention of relapse in depression," Behaviour Research and Therapy, vol. 37, no. 1, pp. S53-S77, 1999.

[84] E. Watkins and J. D. Teasdale, "Adaptive and maladaptive selffocus in depression," Journal of Affective Disorders, vol. 82, no. 1, pp. 1-8, 2004. 
[85] K. A. Rimes and E. Watkins, "The effects of self-focused rumination on global negative self-judgements in depression," Behaviour Research and Therapy, vol. 43, no. 12, pp. 16731681, 2005.

[86] A. Lavender and E. Watkins, "Rumination and future thinking in depression," British Journal of Clinical Psychology, vol. 43, no. 2, pp. 129-142, 2004.

[87] A. D. Williams and M. L. Moulds, "The impact of ruminative processing on the experience of self-referent intrusive memories in dysphoria," Behavior Therapy, vol. 41, no. 1, pp. 38-45, 2010.

[88] C. S. L. Lo, S. M. Y. Ho, and S. D. Hollon, "The effects of rumination and depressive symptoms on the prediction of negative attributional style among college students," Cognitive Therapy and Research, vol. 34, no. 2, pp. 116-123, 2010.

[89] N. Just and L. B. Alloy, "The response styles theory of deression: tests and an extension of the theory," Journal of Abnormal Psychology, vol. 106, no. 2, pp. 221-229, 1997.

[90] C. Kuehner and I. Weber, "Responses to depression in unipolar depressed patients: an investigation of Nolen-Hoeksema's response styles theory," Psychological Medicine, vol. 29, no. 6, pp. 1323-1333, 1999.

[91] S. Nolen-Hoeksema, "The role of rumination in depressive disorders and mixed anxiety/depressive symptoms," Journal of Abnormal Psychology, vol. 109, no. 3, pp. 504-511, 2000.

[92] S. Nolen-Hoeksema, L. E. Parker, and J. Larson, "Ruminative coping with depressed mood following loss," Journal of Personality and Social Psychology, vol. 67, no. 1, pp. 92-104, 1994.

[93] S. Sakamoto, "A longitudinal study of the relationship of self-preoccupation with depression," Journal of Clinical Psychology, vol. 55, no. 1, pp. 109-116, 1999.

[94] R. A. Burwell and S. R. Shirk, "Subtypes of rumination in adolescence: associations between brooding, reflection, depressive symptoms, and coping," Journal of Clinical Child and Adolescent Psychology, vol. 36, no. 1, pp. 56-65, 2007.

[95] J. Spasojević and L. B. Alloy, "Rumination as a common mechanism relating depressive risk factors to depression," Emotion, vol. 1, no. 1, pp. 25-37, 2001.

[96] J. Michalak, A. Hölz, and T. Teismann, "Rumination as a predictor of relapse in mindfulness-based cognitive therapy for depression," Psychology and Psychotherapy, vol. 84, no. 2, pp. 230-236, 2011.

[97] L. B. Alloy, L. Y. Abramson, M. Flynn et al., "Self-focused cognitive styles and bipolar spectrum disorders: concurrent and prospective associations," International Journal of Cognitive Therapy, vol. 2, no. 4, p. 354, 2009.

[98] S. L. Johnson, G. McKenzie, and S. McMurrich, "Ruminative responses to negative and positive affect among students diagnosed with bipolar disorder and major depressive disorder," Cognitive Therapy and Research, vol. 32, no. 5, pp. 702713,2008

[99] G. A. Dori and J. C. Overholser, "Depression, hopelessness, and self-esteem: accounting for suicidality in adolescent psychiatric inpatients," Suicide and Life-Threatening Behavior, vol. 29, no. 4, pp. 309-318, 1999.

[100] J. Johnson, P. A. Gooding, A. M. Wood, and N. Tarrier, "Resilience as positive coping appraisals: testing the schematic appraisals model of suicide (SAMS)," Behaviour Research and Therapy, vol. 48, no. 3, pp. 179-186, 2010.

[101] J. K. Hirsch, K. Wolford, S. M. LaLonde, L. Brunk, and A. Parker-Morris, "Optimistic explanatory style as a moderator of the association between negative life events and suicide ideation," Crisis, vol. 30, no. 1, pp. 48-53, 2009.

[102] C. J. Palmer, "Suicide attempt history, self-esteem, and suicide Risk in a sample of 116 depressed voluntary inpatients," Psychological Reports, vol. 95, no. 3, pp. 1092-1094, 2004.

[103] R. F. Baumeister, "Suicide as escape from self," Psychological Review, vol. 97, no. 1, pp. 90-113, 1990.

[104] N. Fazaa and S. Page, "Personality style and impulsivity as determinants of suicidal subgroups," Archives of Suicide Research, vol. 13, no. 1, pp. 31-45, 2009.

[105] A. Chatard and L. Selimbegović, "When self-destructive thoughts flash through the mind: failure to meet standards affects the accessibility of suicide-related thoughts," Journal of Personality and Social Psychology, vol. 100, no. 4, pp. 587605, 2011.

[106] N. Fazaa and S. Page, "Dependency and self-criticism as predictors of suicidal behavior," Suicide and Life-Threatening Behavior, vol. 33, no. 2, pp. 172-185, 2003.

[107] B. Gawronski and G. V. Bodenhausen, "Associative and propositional processes in evaluation: an integrative review of implicit and explicit attitude change," Psychological Bulletin, vol. 132, no. 5, pp. 692-731, 2006.

[108] B. Egloff and S. C. Schmukle, "Predictive validity of an implicit association test for assessing anxiety," Journal of Personality and Social Psychology, vol. 83, no. 6, pp. 1441-1455, 2002.

[109] J. Gamer, S. C. Schmukle, U. Luka-Krausgrill, and B. Egloff, "Examining the dynamics of the implicit and the explicit selfconcept in social anxiety: changes in the implicit association test-anxiety and the social phobia anxiety inventory following treatment," Journal of Personality Assessment, vol. 90, no. 5, pp. 476-480, 2008.

[110] J. Huijding and P. J. De Jong, "Specific predictive power of automatic spider-related affective associations for controllable and uncontrollable fear responses toward spiders," Behaviour Research and Therapy, vol. 44, no. 2, pp. 161-176, 2006.

[111] M. K. Nock, J. M. Park, C. T. Finn, T. L. Deliberto, H. J. Dour, and M. R. Banaji, "Measuring the suicidal mind: implicit cognition predicts suicidal behavior," Psychological Science, vol. 21, no. 4, pp. 511-517, 2010.

[112] K. Surrence, R. Miranda, B. M. Marroquín, and S. Chan, "Brooding and reflective rumination among suicide attempters: cognitive vulnerability to suicidal ideation," Behaviour Research and Therapy, vol. 47, no. 9, pp. 803-808, 2009.

[113] J. M. Smith, L. B. Alloy, and L. Y. Abramson, "Cognitive vulnerability to depression, rumination, hopelessness, and suicidal ideation: multiple pathways to self-injurious thinking," Suicide and Life-Threatening Behavior, vol. 36, no. 4, pp. 443454, 2006.

[114] C. Crane, T. Barnhofer, and J. M. G. Williams, "Reflection, brooding, and suicidality: a preliminary study of different types of rumination in individuals with a history of major depression," British Journal of Clinical Psychology, vol. 46, no. 4, pp. 497-504, 2007.

[115] A. K. Fairweather, K. J. Anstey, B. Rodgers, A. F. Jorm, and H. Christensen, "Age and gender differences among Australian suicide ideators: prevalence and correlates," Journal of Nervous and Mental Disease, vol. 195, no. 2, pp. 130-136, 2007.

[116] R. Miranda and S. Nolen-Hoeksema, "Brooding and reflection: rumination predicts suicidal ideation at 1-year followup in a community sample," Behaviour Research and Therapy, vol. 45, no. 12, pp. 3088-3095, 2007.

[117] R. C. O’Connor and R. Noyce, "Personality and cognitive processes: self-criticism and different types of rumination 
as predictors of suicidal ideation," Behaviour Research and Therapy, vol. 46, no. 3, pp. 392-401, 2008.

[118] S. Chan, R. Miranda, and K. Surrence, "Subtypes of rumination in the relationship between negative life events and suicidal ideation," Archives of Suicide Research, vol. 13, no. 2, pp. 123-135, 2009.

[119] E. G. Daskalopoulou, D. G. Dikeos, G. N. Papadimitriou et al., "Self-esteem, social adjustment and suicidality in affective disorders," European Psychiatry, vol. 17, no. 5, pp. 265-271, 2002.

[120] N. M. Simon, M. H. Pollack, M. J. Ostacher et al., "Understanding the link between anxiety symptoms and suicidal ideation and behaviors in outpatients with bipolar disorder," Journal of Affective Disorders, vol. 97, no. 1-3, pp. 91-99, 2007.

[121] D. G. Amaral and J. L. Price, "Amygdalo-cortical projections in the monkey (Macaca fascicularis)," Journal of Comparative Neurology, vol. 230, no. 4, pp. 465-496, 1984.

[122] H. Barbas and J. De Olmos, "Projections from the amygdala to basoventral and mediodorsal prefrontal regions in the rhesus monkey," Journal of Comparative Neurology, vol. 300, no. 4, pp. 549-571, 1990.

[123] S. T. Carmichael and J. L. Price, "Limbic connections of the orbital and medial prefrontal cortex in macaque monkeys," Journal of Comparative Neurology, vol. 363, no. 4, pp. 615641, 1995.

[124] L. J. Porrino, A. M. Crane, and P. S. Goldman-Rakic, "Direct and indirect pathways from the amygdala to the frontal lobe in rhesus monkeys," Journal of Comparative Neurology, vol. 198, no. 1, pp. 121-136, 1981.

[125] J. A. Buckwalter, C. M. Schumann, and G. W. Van Hoesen, "Evidence for direct projections from the basal nucleus of the amygdala to retrosplenial cortex in the Macaque monkey," Experimental Brain Research, vol. 186, no. 1, pp. 47-57, 2008.

[126] S. N. Haber, K. Kunishio, M. Mizobuchi, and E. LyndBalta, "The orbital and medial prefrontal circuit through the primate basal ganglia," Journal of Neuroscience, vol. 15, no. 7 I, pp. 4851-4867, 1995.

[127] S. Grimm, P. Boesiger, J. Beck et al., "Altered negative BOLD responses in the default-mode network during emotion processing in depressed subjects," Neuropsychopharmacology, vol. 34, no. 4, pp. 932-943, 2009.

[128] A. Heinzel, F. Bermpohl, R. Niese et al., "How do we modulate our emotions? Parametric fMRI reveals cortical midline structures as regions specifically involved in the processing of emotional valences," Cognitive Brain Research, vol. 25, no. 1, pp. 348-358, 2005.

[129] M. E. Raichle, A. M. MacLeod, A. Z. Snyder, W. J. Powers, D. A. Gusnard, and G. L. Shulman, "A default mode of brain function," Proceedings of the National Academy of Sciences of the United States of America, vol. 98, no. 2, pp. 676-682, 2001.

[130] D. A. Gusnard and M. E. Raichle, "Searching for a baseline: functional imaging and the resting human brain," Nature Reviews Neuroscience, vol. 2, no. 10, pp. 685-694, 2001.

[131] M. K. Johnson, S. Nolen-Hoeksema, K. J. Mitchell, and Y. Levin, "Medial cortex activity, self-reflection and depression," Social Cognitive and Affective Neuroscience, vol. 4, no. 4, Article ID nsp022, pp. 313-327, 2009.

[132] J. Scheuerecker, E. M. Meisenzahl, N. Koutsouleris et al., "Orbitofrontal volume reductions during emotion recognition in patients with major depression," Journal of Psychiatry and Neuroscience, vol. 35, no. 5, pp. 311-320, 2010.

[133] G. S. Smith, E. Kramer, Y. Ma et al., "The functional neuroanatomy of geriatric depression," International Journal of Geriatric Psychiatry, vol. 24, no. 8, pp. 798-808, 2009.
[134] S. Grimm, J. Ernst, P. Boesiger et al., "Increased self-focus in major depressive disorder is related to neural abnormalities in subcortical-cortical midline structures," Human Brain Mapping, vol. 30, no. 8, pp. 2617-2627, 2009.

[135] J. O. Brooks Jr., P. W. Wang, J. C. Bonner et al., “Decreased prefrontal, anterior cingulate, insula, and ventral striatal metabolism in medication-free depressed outpatients with bipolar disorder," Journal of Psychiatric Research, vol. 43, no. 3, pp. 181-188, 2009.

[136] W. C. Drevets, J. L. Price, J. R. Simpson et al., "Subgenual prefrontal cortex abnormalities in mood disorders," Nature, vol. 386, no. 6627, pp. 824-827, 1997.

[137] L. S. Kegeles, K. M. Malone, M. Slifstein et al., "Response of cortical metabolic deficits to serotonergic challenge in familial mood disorders," American Journal of Psychiatry, vol. 160, no. 1, pp. 76-82, 2003.

[138] M. Liotti, H. S. Mayberg, S. McGinnis, S. L. Brannan, and P. Jerabek, "Unmasking disease-specific cerebral blood flow abnormalities: mood challenge in patients with remitted unipolar depression," American Journal of Psychiatry, vol. 159, no. 11, pp. 1830-1840, 2002.

[139] D. A. Pizzagalli, A. J. Holmes, D. G. Dillon et al., "Reduced caudate and nucleus accumbens response to rewards in unmedicated individuals with major depressive disorder," American Journal of Psychiatry, vol. 166, no. 6, pp. 702-710, 2009.

[140] R. T. Dunn, T. A. Kimbrell, T. A. Ketter, M. A. Frye, D. A. Luckenbaugh, and R. M. Post, "Principal components of the beck depression inventory and regional cerebral metabolism in unipolar and bipolar depression," Biological Psychiatry, vol. 51, no. 5, pp. 387-399, 2002.

[141] H. S. Mayberg, S. K. Brannan, J. L. Tekell et al., "Regional metabolic effects of fluoxetine in major depression: serial changes and relationship to clinical response," Biological Psychiatry, vol. 48, no. 8, pp. 830-843, 2000.

[142] J. Wu, M. S. Buchsbaum, J. C. Gillin et al., "Prediction of antidepressant effects of sleep deprivation by metabolic rates in the ventral anterior cingulate and medial prefrontal cortex," American Journal of Psychiatry, vol. 156, no. 8, pp. 1149-1158, 1999.

[143] M. Ritchey, F. Dolcos, K. M. Eddington, T. J. Strauman, and R. Cabeza, "Neural correlates of emotional processing in depression: changes with cognitive behavioral therapy and predictors of treatment response," Journal of Psychiatric Research, vol. 45, no. 5, pp. 577-587, 2011.

[144] M. J. Smoski, J. Felder, J. Bizzell et al., "fMRI of alterations in reward selection, anticipation, and feedback in major depressive disorder," Journal of Affective Disorders, vol. 118, no. 1-3, pp. 69-78, 2009.

[145] E. A. Osuch, R. L. Bluhm, P. C. Williamson, J. Théberge, M. Densmore, and R. W. J. Neufeld, "Brain activation to favorite music in healthy controls and depressed patients," NeuroReport, vol. 20, no. 13, pp. 1204-1208, 2009.

[146] M. N. Pavuluri, A. M. Passarotti, E. M. Harral, and J. A. Sweeney, "An fMRI study of the neural correlates of incidental versus directed emotion processing in pediatric bipolar disorder," Journal of the American Academy of Child and Adolescent Psychiatry, vol. 48, no. 3, pp. 308-319, 2009.

[147] G. S. Malhi, J. Lagopoulos, P. B. Ward et al., "Cognitive generation of affect in bipolar depression: an fMRI study," European Journal of Neuroscience, vol. 19, no. 3, pp. 741-754, 2004.

[148] C. H. Chen, B. Lennox, R. Jacob et al., "Explicit and implicit facial affect recognition in manic and depressed states of 
bipolar disorder: a functional magnetic resonance imaging study," Biological Psychiatry, vol. 59, no. 1, pp. 31-39, 2006.

[149] P. J. Monks, J. M. Thompson, E. T. Bullmore et al., "A functional MRI study of working memory task in euthymic bipolar disorder: evidence for task-specific dysfunction," Bipolar Disorders, vol. 6, no. 6, pp. 550-564, 2004.

[150] C. M. Adler, S. K. Holland, V. Schmithorst, M. J. Tuchfarber, and S. M. Strakowski, "Changes in neuronal activation in patients with bipolar disorder during performance of a working memory task," Bipolar Disorders, vol. 6, no. 6, pp. 540$549,2004$.

[151] N. S. Lawrence, A. M. Williams, S. Surguladze et al., "Subcortical and ventral prefrontal cortical neural responses to facial expressions distinguish patients with bipolar disorder and major depression," Biological Psychiatry, vol. 55, no. 6, pp. 578-587, 2004.

[152] F. Benedetti, A. Bernasconi, V. Blasi et al., "Neural and genetic correlates of antidepressant response to sleep deprivation: a functional magnetic resonance imaging study of moral valence decision in bipolar depression," Archives of General Psychiatry, vol. 64, no. 2, pp. 179-187, 2007.

[153] W. R. Marchand, J. N. Lee, C. Garn et al., "Aberrant emotionalprocessing in posterior cortical midline structures inbipolar II depression," Progress in Neuro-Psychopharmacology and Biological Psychiatry, vol. 35, no. 7, pp. 1729-1737, 1729.

[154] F. Wang, J. H. Kalmar, Y. He et al., "Functional and structural connectivity between the perigenual anterior cingulate and amygdala in bipolar disorder," Biological Psychiatry, vol. 66, no. 5, pp. 516-521, 2009.

[155] L. Altshuler, S. Bookheimer, J. Townsend et al., "Regional brain changes in bipolar I depression: a functional magnetic resonance imaging study," Bipolar Disorders, vol. 10, no. 6, pp. 708-717, 2008.

[156] L. L. Altshuler, S. Y. Bookheimer, J. Townsend et al., "Blunted activation in orbitofrontal cortex during mania: a functional magnetic resonance imaging study," Biological Psychiatry, vol. 58, no. 10, pp. 763-769, 2005.

[157] R. Elliott, A. Ogilvie, J. S. Rubinsztein, G. Calderon, R. J. Dolan, and B. J. Sahakian, "Abnormal ventral frontal response during performance of an affective go/no go task in patients with mania," Biological Psychiatry, vol. 55, no. 12, pp. 1163-1170, 2004.

[158] B. R. Lennox, R. Jacob, A. J. Calder, V. Lupson, and E. T. Bullmore, "Behavioural and neurocognitive responses to sad facial affect are attenuated in patients with mania," Psychological Medicine, vol. 34, no. 5, pp. 795-802, 2004.

[159] C. Lemogne, P. Gorwood, L. Bergouignan, A. Pelissolo, S. Lehericy, and P. Fossati, "Negative affectivity, self-referentialprocessing and the cortical midline structures," Social Cognitive \& Affective Neuroscience, vol. 6, no. 4, pp. 426-433, 2011.

[160] S. Yoshimura, Y. Okamoto, K. Onoda et al., "Rostral anterior cingulate cortex activity mediates the relationship between the depressive symptoms and the medial prefrontal cortex activity," Journal of Affective Disorders, vol. 122, no. 1-2, pp. 76-85, 2010.

[161] R. E. Cooney, J. Joormann, F. Eugène, E. L. Dennis, and I. H. Gotlib, "Neural correlates of rumination in depression," Cognitive, Affective and Behavioral Neuroscience, vol. 10, no. 4, pp. 470-478, 2010.

[162] J. Lagopoulos and G. Malhi, "Impairments in "top-down" processing in bipolar disorder: a simultaneous fMRI-GSR study," Psychiatry Research, vol. 192, no. 2, pp. 100-108, 2011.
[163] M. Haldane, J. Jogia, A. Cobb, E. Kozuch, V. Kumari, and S. Frangou, "Changes in brain activation during working memory and facial recognition tasks in patients with bipolar disorder with Lamotrigine monotherapy," European Neuropsychopharmacology, vol. 18, no. 1, pp. 48-54, 2008.

[164] J. Jogia, M. Haldane, A. Cobb, V. Kumari, and S. Frangou, "Pilot investigation of the changes in cortical activation during facial affect recognition with lamotrigine monotherapy in bipolar disorder," British Journal of Psychiatry, vol. 192, no. 3, pp. 197-201, 2008.

[165] G. M. Goodwin, J. T. O. Cavanagh, M. F. Glabus, R. F. Kehoe, R. E. O'Carroll, and K. P. Ebmeier, "Uptake of 99mTc-exametazime shown by single photon emission computed tomography before and after lithium withdrawal in bipolar patients: associations with mania," British Journal of Psychiatry, vol. 170, pp. 426-430, 1997.

[166] W. R. Marchand, "Cortico-basal ganglia circuitry: a review of key research and implications for functional connectivity studies of mood and anxiety disorders," Brain Structure and Function, vol. 215, no. 2, pp. 73-96, 2010.

[167] W. R. Marchand and D. Yurgelun-Todd, "Striatal structure and function in mood disorders: a comprehensive review," Bipolar Disorders, vol. 12, no. 8, pp. 764-785, 2010.

[168] W. R. Marchand, J. N. Lee, C. Garn et al., "Striatal and cortical midline activation and connectivity associated with suicidal ideation and depression in bipolar II disorder," Journal of Affective Disorders, vol. 133, no. 3, pp. 638-645, 2011.

[169] Z. Jia, X. Huang, Q. Wu et al., "High-field magnetic resonance imaging of suicidality in patients with major depressive disorder," American Journal of Psychiatry, vol. 167, no. 11, pp. 1381-1390, 2010.

[170] G. Wagner, K. Koch, C. Schachtzabel, C. C. Schultz, H. Sauer, and R. G. Schlösser, "Structural brain alterations in patients with major depressive disorder and high risk for suicide: evidence for a distinct neurobiological entity?" NeuroImage, vol. 54, no. 2, pp. 1607-1614, 2011.

[171] J. P. Hwang, T. W. Lee, S. J. Tsai et al., "Cortical and subcortical abnormalities in late-onset depression with history of suicide attempts investigated with MRI and voxel-based morphometry," Journal of Geriatric Psychiatry and Neurology, vol. 23, no. 3, pp. 171-184, 2010.

[172] K. Y. Vinod, S. A. Kassir, B. L. Hungund, T. B. Cooper, J. J. Mann, and V. Arango, "Selective alterations of the CB1 receptors and the fatty acid amide hydrolase in the ventral striatum of alcoholics and suicides," Journal of Psychiatric Research, vol. 44, no. 9, pp. 591-597, 2010.

[173] A. T. Ferry, D. Öngür, X. An, and J. L. Price, "Prefrontal cortical projections to the striatum in macaque monkeys: evidence for an organization related to prefrontal networks," Journal of Comparative Neurology, vol. 425, no. 3, pp. 447470, 2000.

[174] W. R. Marchand, J. N. Lee, J. W. Thatcher et al., "Putamen coactivation during motor task execution," NeuroReport, vol. 19, no. 9, pp. 957-960, 2008.

[175] A. Chiesa and P. Malinowski, "Mindfulness-based approaches: are they all the same?" Journal of Clinical Psychology, vol. 67, no. 4, pp. 404-424, 2011.

[176] S. R. Bishop, M. Lau, S. Shapiro et al., "Mindfulness: a proposed operational definition," Clinical Psychology, vol. 11, no. 3, pp. 230-241, 2004.

[177] P. Salmon, S. Sephton, I. Weissbecker, K. Hoover, C. Ulmer, and J. L. Studts, "Mindfulness meditation in clinical practice," Cognitive and Behavioral Practice, vol. 11, no. 4, pp. 434-446, 2004. 
[178] Z. V. Segal, J. M. G. Williams, and J. D. Teasdale, MindfulnessBased Cognitive Therapy for Depression: A New Approach to Preventing Relapse, Guilford Press, New York, NY, USA, 2002.

[179] P. R. Goldin and J. J. Gross, "Effects of mindfulness-based stress reduction (MBSR) on emotion regulation in social anxiety disorder," Emotion, vol. 10, no. 1, pp. 83-91, 2010.

[180] S. Evans, S. Ferrando, M. Findler, C. Stowell, C. Smart, and D. Haglin, "Mindfulness-based cognitive therapy for generalized anxiety disorder," Journal of Anxiety Disorders, vol. 22, no. 4, pp. 716-721, 2008.

[181] C. R. Gross, M. J. Kreitzer, M. Reilly-Spong et al., "Mindfulness-based stress reduction versus pharmacotherapy for chronic primary insomnia: a randomized controlled clinical trial," The Journal of Science and Healing, vol. 7, no. 2, pp. 76-87, 2011.

[182] K. Birnie, S. N. Garland, and L. E. Carlson, "Psychological benefits for cancer patients and their partners participating in mindfulness-based stress reduction (MBSR)," Psycho-Onco$\log y$, vol. 19, no. 9, pp. 1004-1009, 2010.

[183] G. Esmer, J. Blum, J. Rulf, and J. Pier, "Mindfulness-based stress reduction for failed back surgery syndrome: a randomized controlled trial," Journal of the American Osteopathic Association, vol. 110, no. 11, pp. 646-652, 2010.

[184] C. R. Gross, M. J. Kreitzer, W. Thomas et al., "Mindfulnessbased stress reduction for solid organ transplant recipients: a randomized controlled trial," Alternative Therapies in Health and Medicine, vol. 16, no. 5, pp. 30-38, 2010.

[185] H. M. Joo, S. J. Lee, Y. G. Chung, and I. Y. Shin, "Effects of mindfulness based stress reduction program on depression, anxiety and stress in patients with aneurysmal subarachnoid hemorrhage," Journal of Korean Neurosurgical Society, vol. 47, no. 5, pp. 345-351, 2010.

[186] C. A. Lengacher, V. Johnson-Mallard, J. Post-White et al., "Randomized controlled trial of mindfulness-based stress reduction (MBSR) for survivors of breast cancer," PsychoOncology, vol. 18, no. 12, pp. 1261-1272, 2009.

[187] P. Grossman, U. Tiefenthaler-Gilmer, A. Raysz, and U. Kesper, "Mindfulness training as an intervention for fibromyalgia: evidence of postintervention and 3-year follow-up benefits in well-being," Psychotherapy and Psychosomatics, vol. 76, no. 4, pp. 226-233, 2007.

[188] S. E. Sephton, P. Salmon, I. Weissbecker et al., "Mindfulness meditation alleviates depressive symptoms in women with fibromyalgia: results of a randomized clinical trial," Arthritis Care and Research, vol. 57, no. 1, pp. 77-85, 2007.

[189] T. S. Campbell, L. E. Labelle, S. L. Bacon, P. Faris, and L. E. Carlson, "Impact of mindfulness-based stress reduction (MBSR) on attention, rumination and resting blood pressure in women with cancer: a waitlist-controlled study," Journal of Behavioral Medicine. In press.

[190] L. E. Carlson, M. Speca, P. Faris, and K. D. Patel, “One year pre-post intervention follow-up of psychological, immune, endocrine and blood pressure outcomes of mindfulnessbased stress reduction (MBSR) in breast and prostate cancer outpatients," Brain, Behavior, and Immunity, vol. 21, no. 8, pp. 1038-1049, 2007.

[191] L. E. Carlson and S. N. Garland, "Impact of mindfulnessbased stress reduction (MBSR) on sleep, mood, stress and fatigue symptoms in cancer outpatients," International Journal of Behavioral Medicine, vol. 12, no. 4, pp. 278-285, 2005.

[192] D. Ledesma and H. Kumano, "Mindfulness-based stress reduction and cancer: a meta-analysis," Psycho-Oncology, vol. 18 , no. 6, pp. 571-579, 2009.
[193] B. Gayner, M. J. Esplen, P. Deroche et al., "A randomized controlled trial of mindfulness-based stress reduction to manage affective symptoms and improve quality of life in gay men living with HIV," Journal of Behavioral Medicine. In press.

[194] K. F. Flugel Colle, A. Vincent, S. S. Cha, L. L. Loehrer, B. A. Bauer, and D. L. Wahner-Roedler, "Measurement of quality of life and participant experience with the mindfulnessbased stress reduction program," Complementary Therapies in Clinical Practice, vol. 16, no. 1, pp. 36-40, 2010.

[195] S. Rosenzweig, J. M. Greeson, D. K. Reibel, J. S. Green, S. A. Jasser, and D. Beasley, "Mindfulness-based stress reduction for chronic pain conditions: variation in treatment outcomes and role of home meditation practice," Journal of Psychosomatic Research, vol. 68, no. 1, pp. 29-36, 2010.

[196] D. M. Perlman, T. V. Salomons, R. J. Davidson, and A. Lutz, "Differential effects on pain intensity and unpleasantness of two meditation practices," Emotion, vol. 10, no. 1, pp. 65-71, 2010.

[197] S. Ernst, J. Welke, C. Heintze et al., "Effects of mindfulnessbased stress reduction on quality of life in nursing home residents: a feasibility study," Forschende Komplementarmedizin, vol. 15, no. 2, pp. 74-81, 2008.

[198] A. Chiesa and A. Serretti, "Mindfulness-based stress reduction for stress management in healthy people: a review and meta-analysis," Journal of Alternative and Complementary Medicine, vol. 15, no. 5, pp. 593-600, 2009.

[199] G. Bondolfi, F. Jermann, M. V. der Linden et al., "Depression relapse prophylaxis with mindfulness-based cognitive therapy: replication and extension in the Swiss health care system," Journal of Affective Disorders, vol. 122, no. 3, pp. 224231, 2010.

[200] K. A. Godfrin and C. van Heeringen, "The effects of mindfulness-based cognitive therapy on recurrence of depressive episodes, mental health and quality of life: a randomized controlled study," Behaviour Research and Therapy, vol. 48, no. 8, pp. 738-746, 2010.

[201] W. Kuyken, S. Byford, R. S. Taylor et al., "Mindfulness-based cognitive therapy to prevent relapse in recurrent depression," Journal of Consulting and Clinical Psychology, vol. 76, no. 6, pp. 966-978, 2008.

[202] V. Manicavasgar, G. Parker, and T. Perich, "Mindfulnessbased cognitive therapy vs cognitive behaviour therapy as a treatment for non-melancholic depression," Journal of Affective Disorders, vol. 130, no. 1-2, pp. 138-144, 2011.

[203] K. L. Mathew, H. S. Whitford, M. A. Kenny, and L. A. Denson, "The long-term effects of mindfulness-based cognitive therapy as a relapse prevention treatment for major depressive disorder," Behavioural and Cognitive Psychotherapy, vol. 38, no. 5, pp. 561-576, 2010.

[204] Z. V. Segal, P. Bieling, T. Young et al., "Antidepressant monotherapy vs sequential pharmacotherapy and mindfulnessbased cognitive therapy, or placebo, for relapse prophylaxis in recurrent depression," Archives of General Psychiatry, vol. 67, no. 12, pp. 1256-1264, 2010.

[205] B. Kim, S. H. Lee, Y. W. Kim et al., "Effectiveness of a mindfulness-based cognitive therapy program as an adjunct to pharmacotherapy in patients with panic disorder," Journal of Anxiety Disorders, vol. 24, no. 6, pp. 590-595, 2010.

[206] D. A. Lovas and A. J. Barsky, "Mindfulness-based cognitive therapy for hypochondriasis, or severe health anxiety: a pilot study," Journal of Anxiety Disorders, vol. 24, no. 8, pp. 931935, 2010. 
[207] J. Piet, E. Hougaard, M. S. Hecksher, and N. K. Rosenberg, “A randomized pilot study of mindfulness-based cognitive therapy and group cognitive-behavioral therapy for young adults with social phobia," Scandinavian Journal of Psychology, vol. 51, no. 5, pp. 403-410, 2010.

[208] A. Chiesa and A. Serretti, "Mindfulness based cognitive therapy for psychiatric disorders: a systematic review and meta-analysis," Psychiatry Research, vol. 187, no. 3, pp. 441453, 2011.

[209] T. Barnhofer, C. Crane, E. Hargus, M. Amarasinghe, R. Winder, and J. M. G. Williams, "Mindfulness-based cognitive therapy as a treatment for chronic depression: a preliminary study," Behaviour Research and Therapy, vol. 47, no. 5, pp. 366-373, 2009.

[210] J. M. G. Williams, D. S. Duggan, C. Crane, and M. J. V. Fennell, "Mindfulness-based cognitive therapy for prevention of recurrence of suicidal behavior," Journal of Clinical Psychology, vol. 62, no. 2, pp. 201-210, 2006.

[211] T. Barnhofer, D. Duggan, C. Crane, S. Hepburn, M. J. V. Fennell, and J. M. G. Williams, "Effects of meditation on frontal $\alpha$-asymmetry in previously suicidal individuals," NeuroReport, vol. 18, no. 7, pp. 709-712, 2007.

[212] S. R. Hepburn, C. Crane, T. Barnhofer, D. S. Duggan, M. J. V. Fennell, and J. M. G. Williams, "Mindfulness-based cognitive therapy may reduce thought suppression in previously suicidal participants: findings from a preliminary study," British Journal of Clinical Psychology, vol. 48, no. 2, pp. 209-215, 2009.

[213] E. Hargus, C. Crane, T. Barnhofer, and J. M. G. Williams, "Effects of mindfulness on meta-awareness and specificity of describing prodromal symptoms in suicidal depression," Emotion, vol. 10, no. 1, pp. 34-42, 2010.

[214] J. M. G. Williams, I. T. Russell, C. Crane et al., "Staying well after depression: trial design and protocol," BMC Psychiatry, vol. 10, article 23, 2010.

[215] K. Hawton, L. Sutton, C. Haw, J. Sinclair, and L. Harriss, "Suicide and attempted suicide in bipolar disorder: a systematic review of risk factors," Journal of Clinical Psychiatry, vol. 66, no. 6, pp. 693-704, 2005.

[216] E. J. Kilbane, N. S. Gokbayrak, I. Galynker, L. Cohen, and S. Tross, "A review of panic and suicide in bipolar disorder: does comorbidity increase risk?" Journal of Affective Disorders, vol. 115, no. 1-2, pp. 1-10, 2009.

[217] G. S. Leverich, L. L. Altshuler, M. A. Frye et al., "Factors associated with suicide attempts in 648 patients with bipolar disorder in the Stanley Foundation bipolar network," Journal of Clinical Psychiatry, vol. 64, no. 5, pp. 506-515, 2003.

[218] A. Chiesa, P. Brambilla, and A. Serretti, "Neuro-imaging of mindfulness meditations: implications for clinical practice," Epidemiology and Psychiatric Science, vol. 20, pp. 205-210, 2011.

[219] W. K. Kit, The Complete Book of Zen, Tuttle Publishing, Boston, Mass, USA, 2001.

[220] O. Sogen, An Introduction to Zen Training: A Translation of Sanzen Nyumon, Tuttle Publishing, Boston, Mass, USA, 2001.

[221] M. B. Ospina, K. Bond, M. Karkhaneh et al., "Meditation practices for health: state of the research," Evidence Report/ Technology Assessment 155, 2007.

[222] H. Y. Huang and P. C. Lo, "EEG dynamics of experienced Zen meditation practitioners probed by complexity index and spectral measure," Journal of Medical Engineering and Technology, vol. 33, no. 4, pp. 314-321, 2009.

[223] A. Chiesa, "Zen meditation: an integration of current evidence," Journal of Alternative and Complementary Medicine, vol. 15, no. 5, pp. 585-592, 2009.
[224] T. Murata, T. Takahashi, T. Hamada et al., "Individual trait anxiety levels characterizing the properties of Zen meditation," Neuropsychobiology, vol. 50, no. 2, pp. 189-194, 2004.

[225] E. H. Kozasa, J. Radvany, M. Â. M. Barreiros, J. R. Leite, and E. Amaro, "Preliminary functional magnetic resonance imaging Stroop task results before and after a Zen meditation retreat," Psychiatry and Clinical Neurosciences, vol. 62, no. 3, p. 366, 2008.

[226] J. A. Grant, J. Courtemanche, and P. Rainville, "A nonelaborative mental stance and decoupling of executive and pain-related cortices predicts low pain sensitivity in Zen meditators," Pain, vol. 152, no. 1, pp. 150-156, 2011.

[227] X. Yu, M. Fumoto, Y. Nakatani et al., "Activation of the anterior prefrontal cortex and serotonergic system is associated with improvements in mood and EEG changes induced by Zen meditation practice in novices," International Journal of Psychophysiology, vol. 80, no. 2, pp. 103-111, 2011.

[228] G. Pagnoni, M. Cekic, and Y. Guo, “"Thinking about notthinking": neural correlates of conceptual processing during Zen meditation," PLoS One, vol. 3, no. 9, Article ID e3083, 2008.

[229] J. A. Grant, J. Courtemanche, E. G. Duerden, G. H. Duncan, and P. Rainville, "Cortical thickness and pain sensitivity in Zen meditators," Emotion, vol. 10, no. 1, pp. 43-53, 2010.

[230] G. Pagnoni and M. Cekic, "Age effects on gray matter volume and attentional performance in Zen meditation," Neurobiology of Aging, vol. 28, no. 10, pp. 1623-1627, 2007.

[231] D. J. J. Wang, H. Rao, M. Korczykowski et al., "Cerebral blood flow changes associated with different meditation practices and perceived depth of meditation," Psychiatry Research, vol. 191, no. 1, pp. 60-67, 2011.

[232] K. B. Bærentsen, H. Stødkilde-Jørgensen, B. Sommerlund et al., "An investigation of brain processes supporting meditation," Cognitive Processing, vol. 11, no. 1, pp. 57-84, 2010.

[233] F. Zeidan, K. T. Martucci, R. A. Kraft, N. S. Gordon, J. G. Mchaffie, and R. C. Coghill, "Brain mechanisms supporting the modulation of pain by mindfulness meditation," Journal of Neuroscience, vol. 31, no. 14, pp. 5540-5548, 2011.

[234] V. L. Ives-Deliperi, M. Solms, and E. M. Meintjes, "The neural substrates of mindfulness: an fMRI investigation," Social Neuroscience, vol. 6, no. 3, pp. 231-242, 2011.

[235] B. K. Hölzel, U. Ott, H. Hempel et al., "Differential engagement of anterior cingulate and adjacent medial frontal cortex in adept meditators and non-meditators," Neuroscience Letters, vol. 421, no. 1, pp. 16-21, 2007.

[236] D. V. Chavan, "Vipassana: the Buddha's tool to probe mind and body," Progress in Brain Research, vol. 168, pp. 247-253, 2008.

[237] N. A. S. Farb, Z. V. Segal, H. Mayberg et al., "Attending to the present: mindfulness meditation reveals distinct neural modes of self-reference," Social Cognitive and Affective Neuroscience, vol. 2, no. 4, pp. 313-322, 2007.

[238] L. A. Kilpatrick, B. Y. Suyenobu, S. R. Smith et al., "Impact of mindfulness-based stress reduction training on intrinsic brain connectivity," NeuroImage, vol. 56, no. 1, pp. 290-298, 2011.

[239] B. K. Hölzel, J. Carmody, M. Vangel et al., "Mindfulness practice leads to increases in regional brain gray matter density," Psychiatry Research, vol. 191, no. 1, pp. 36-43, 2011.

[240] B. K. Hölzel, J. Carmody, K. C. Evans et al., "Stress reduction correlates with structural changes in the amygdala," Social Cognitive and Affective Neuroscience, vol. 5, no. 1, pp. 11-17, 2009. 
[241] N. A. S. Farb, A. K. Anderson, H. Mayberg, J. Bean, D. McKeon, and Z. V. Segal, "Minding one's emotions: mindfulness training alters the neural expression of sadness," Emotion, vol. 10, no. 1, pp. 25-33, 2010.

[242] A. R. Rosa, M. Reinares, E. E. Michalak et al., "Functional impairment and disability across mood states in bipolar disorder," Value in Health, vol. 13, no. 8, pp. 984-988, 2010.

[243] L. Gutiérrez-Rojas, D. Jurado, and M. Gurpegui, "Factors associated with work, social life and family life disability in bipolar disorder patients," Psychiatry Research, vol. 186, no. 2-3, pp. 254-260, 2011.

[244] J. Sanchez-Moreno, A. Martinez-Aran, R. Tabarés-Seisdedos, C. Torrent, E. Vieta, and J. L. Ayuso-Mateos, "Functioning and disability in bipolar disorder: an extensive review," Psychotherapy and Psychosomatics, vol. 78, no. 5, pp. 285-297, 2009.

[245] K. N. Fountoulakis, H. Grunze, P. Panagiotidis, and G. Kaprinis, “Treatment of bipolar depression: an update," Journal of Affective Disorders, vol. 109, no. 1-2, pp. 21-34, 2008.

[246] D. M. Hilty, M. H. Leamon, R. F. Lim, R. H. Kelly, and R. E. Hales, "A review of bipolar disorder in adults," Psychiatry, vol. 3, pp. 43-55, 2006.

[247] G. S. Sachs, "Unmet clinical needs in bipolar disorder," Journal of Clinical Psychopharmacology, vol. 23, no. 3, pp. S2-S8, 2003.

[248] L. S. Kleinman, A. Lowin, E. Flood, G. Gandhi, E. Edgell, and D. A. Revicki, "Costs of bipolar disorder," PharmacoEconomics, vol. 21, no. 9, pp. 601-622, 2003.

[249] R. J. Baldessarini, E. Vieta, J. R. Calabrese, M. Tohen, and C. L. Bowden, "Bipolar depression: overview and commentary," Harvard Review of Psychiatry, vol. 18, no. 3, pp. 143-157, 2010.

[250] R. M. Post, “The impact of bipolar depression,” Journal of Clinical Psychiatry, vol. 66, supplement 5, pp. 5-10, 2005.

[251] Z. Rihmer, E. Szadoczky, J. Furedi, K. Kiss, and Z. Papp, "Anxiety disorders comorbidity in bipolar I, bipolar II and unipolar major depression: results from a population-based study in Hungary," Journal of Affective Disorders, vol. 67, no. 1-3, pp. 175-179, 2001.

[252] S. Pini, G. B. Cassano, E. Simonini, M. Savino, A. Russo, and S. A. Montgomery, "Prevalence of anxiety disorders comorbidity in bipolar depression, unipolar depression and dysthymia," Journal of Affective Disorders, vol. 42, no. 2-3, pp. 145-153, 1997.

[253] J. M. Azorin, A. Kaladjian, N. Besnier et al., "Suicidal behaviour in a French Cohort of major depressive patients: characteristics of attempters and nonattempters," Journal of Affective Disorders, vol. 123, no. 1-3, pp. 87-94, 2010.

[254] M. Pompili, Z. Rihmer, M. Innamorati, D. Lester, P. Girardi, and R. Tatarelli, "Assessment and treatment of suicide risk in bipolar disorders," Expert Review of Neurotherapeutics, vol. 9, no. 1, pp. 109-136, 2009. 


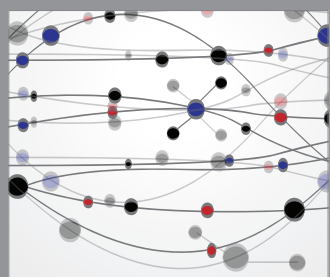

The Scientific World Journal
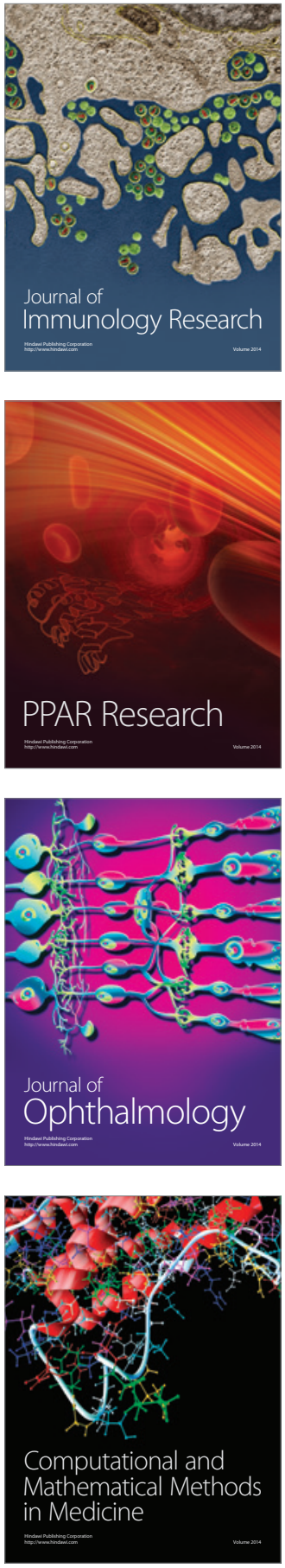

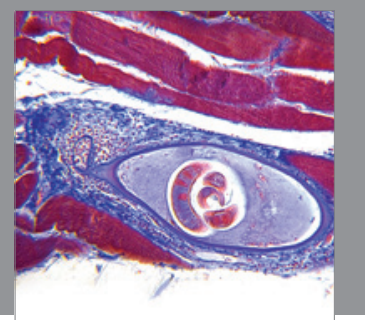

Gastroenterology

Research and Practice
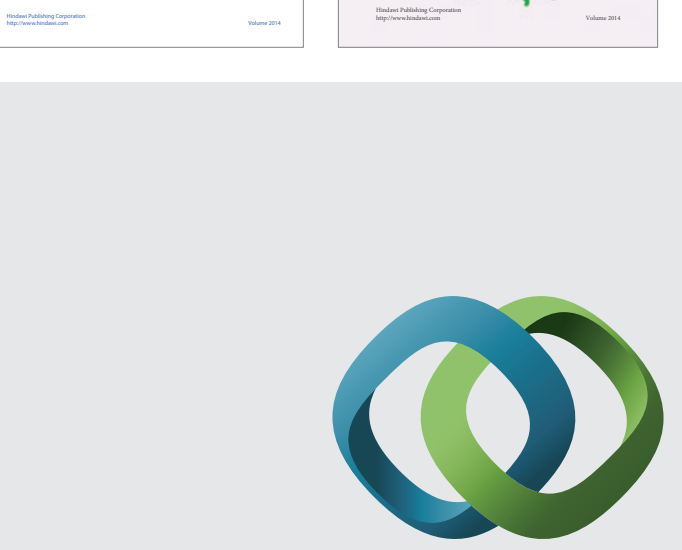

\section{Hindawi}

Submit your manuscripts at

http://www.hindawi.com
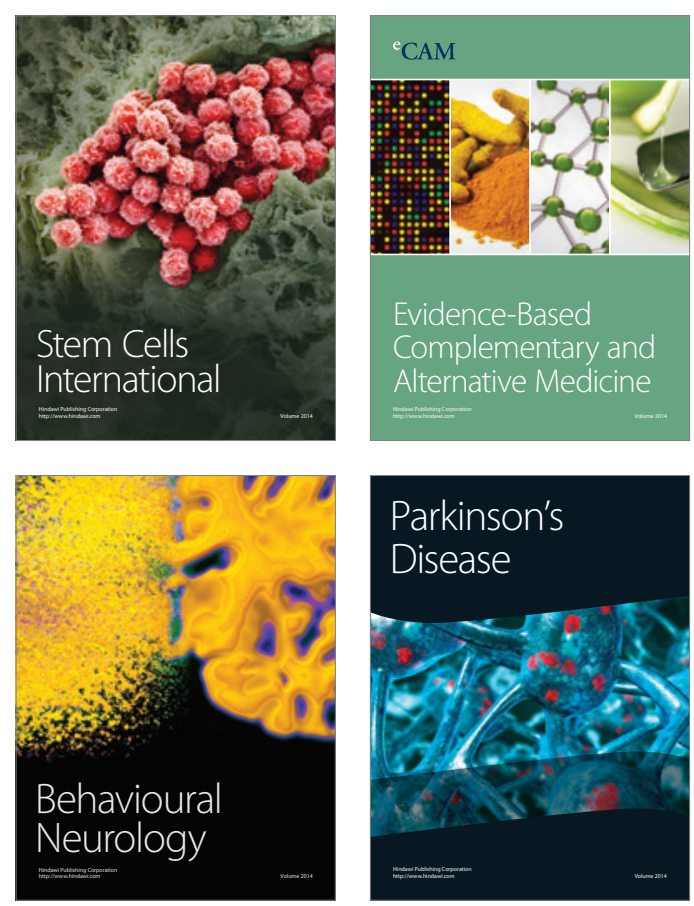

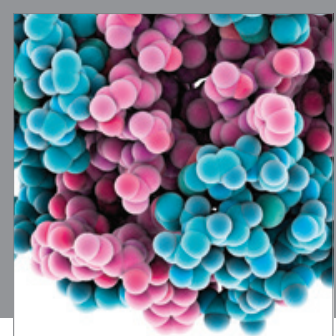

Journal of
Diabetes Research

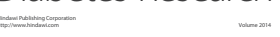

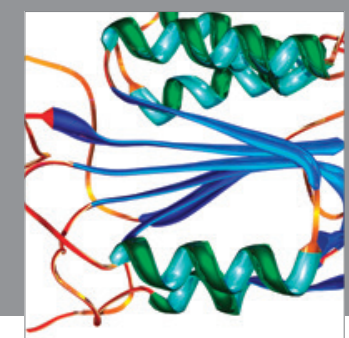

Disease Markers
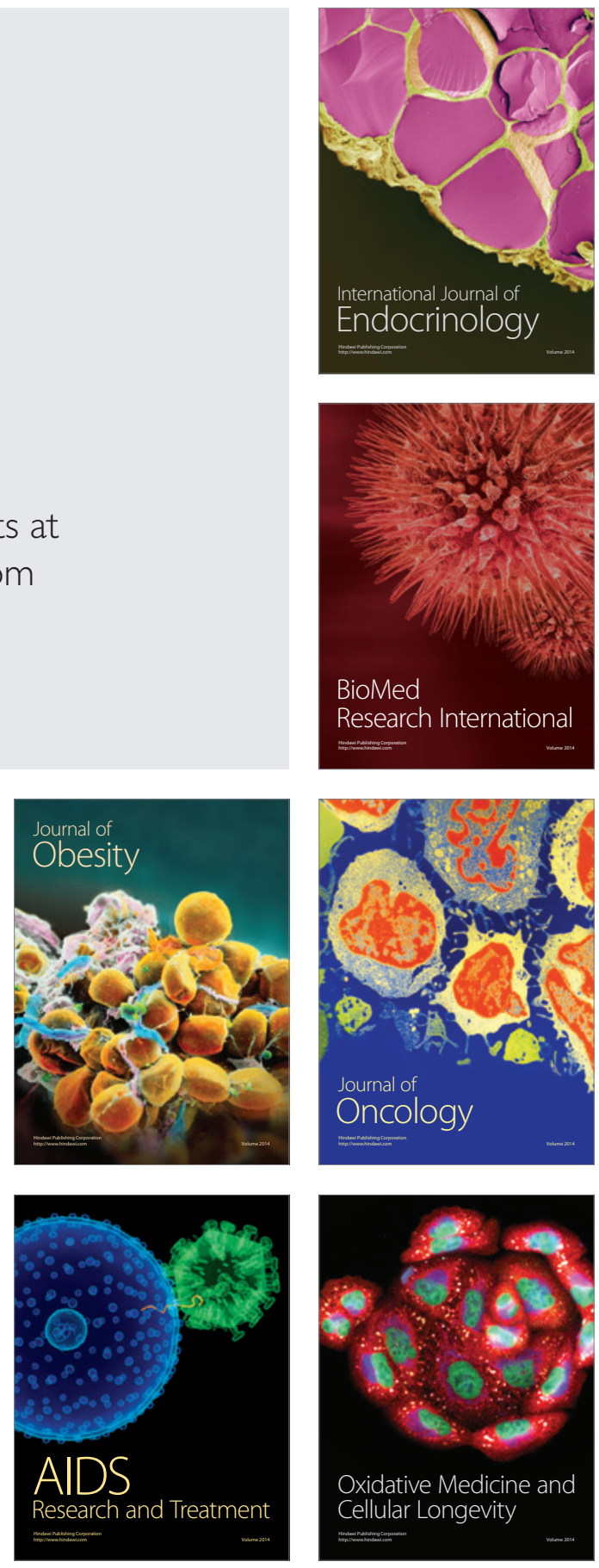